This is the final peer-reviewed accepted manuscript of:

Valentina Marassi, Matteo Marangon, Andrea Zattoni, Simone Vincenzi, Andrea Versari, Pierluigi Reschiglian, Barbara Roda, Andrea Curioni

"Characterization of red wine native colloids by asymmetrical flow field-flow fractionation with online multidetection"

which has been published in final form in Food Hydrocolloids 2021, vol. 110, article n. 106204

The final published version is available online at:

https://doi.org/10.1016/i.foodhyd.2020.106204

(C) 2020 Elsevier. This manuscript version is made available under the Creative Commons Attribution-NonCommercial-NoDerivs (CC BY-NC-ND) 4.0 International License (http://creativecommons.org/licenses/by-nc-nd/4.0/) 


\title{
Characterization of red wine native colloids by asymmetrical flow field-flow fractionation with online multidetection
}

\author{
Valentina Marassi ${ }^{\mathrm{a}, \mathrm{b}}$, Matteo Marangon ${ }^{\mathrm{c}, *}$, Andrea Zattoni ${ }^{\mathrm{a}, \mathrm{b}}$, Simone Vincenzi ${ }^{\mathrm{c}, \mathrm{e}}$, \\ Andrea Versari $^{\mathrm{d}}$, Pierluigi Reschiglian ${ }^{\mathrm{a}, \mathrm{b}}$, Barbara Roda ${ }^{\mathrm{a}, \mathrm{b}}$, Andrea Curioni ${ }^{\mathrm{c}, \mathrm{e}}$ \\ a Department of Chemistry "G. Ciamician", University of Bologna, Via Selmi 2, 40126, Bologna, Italy \\ ${ }^{\mathrm{b}}$ byFlow srl, Via dell'Arcoveggio 74, 40129, Bologna, Italy \\ ${ }^{\mathrm{c}}$ Department of Agronomy, Food, Natural Resources, Animals and Environment (DAFNAE), University of Padova, Viale dell'Università 16, 35020, Padova, Italy \\ ${ }^{\mathrm{d}}$ Department of Agricultural and Food Sciences, University of Bologna, Piazza Goidanich 60, Cesena, FC, 47521, Italy \\ ${ }^{\mathrm{e}}$ Centre for Research in Viticulture and Enology (CIRVE), Viale XXVIII Aprile 14, 31015, Conegliano, Italy
}

\begin{abstract}
A B S T R A C T
Colloids are an important component of wines, but their study is challenging due to their instability. Asym metrical Flow-Field Flow Fractionation (AF4)-multidetection is here proposed as a suitable approach to isolate and characterize red wine colloids in native state. AF4 provided size-separation and enabled quantification of the colloidal content of two wines. The gyration radius of colloids was determined by multi-angle light scattering, and ranged between 25 and $50 \mathrm{~nm}$. Analysis of the collected AF4-fractions showed that proteins, polysaccharides and phenolics were present in different proportions among fractions. The composition of AF4-fractions differed between wines. SDS-PAGE analysis of AF4-fractions indicated the presence of protein-phenolics sub-aggregates only in the fractions containing colloids with small radius. The results allowed proposing a model for red wine colloids structure, which comprises two coexisting entities, one made of covalently linked proteins-phenolics subaggregates interacting by non-covalent forces with polysaccharides, and a second in which only polysaccharides and phenolics are present. The proposed model is consistent with the reported relative stability of red wine proteins, a fact that can be due to the stabilizing activity of polysaccharides. Given that enological practices affect the extraction of proteins, polysaccharides and phenolics, AF4-technique represents a very promising tool to investigate the effects of these practices on wine colloidal aggregation and behavior.
\end{abstract}

\author{
Keywords: \\ Red wine \\ Colloids \\ Flow-field flow fractionation \\ Multi angle light scattering \\ Macromolecules \\ Phenolics
}

\section{Introduction}

Colloidal particles in wine impact its physico-chemical properties including stability, taste and mouthfeel, and their content can vary greatly depending on the grape characteristics and vinification practices (Del Barrio-Galán, Medel-Marabolí, \& Peña-Neira, 2015; Martínez-Lapuente, Guadalupe, \& Ayestarán, 2019; Mierczynska-Vasilev \& Smith, 2015; Vernhet, 2019). Wine colloidal particles originate from the interactions of macromolecules as proteins, polysaccharides and condensed tannins. Wine macromolecules potentially participating in colloidal particle formation are heterogeneous as they can originate from grapes, from yeast, from bacteria, or they can be introduced to, or removed from, the wine as a result of winemaking practices as use of additives or wine fining. Given that within each of the sources above mentioned a huge variability exists, the type, amount and relative concentration of macromolecules in any given wine varies greatly. To complicate things further, wine proteins and polysaccharides are known to interact differently with phenolics, which comprise hundreds of compounds with different properties and sizes (Kassara, Li, Smith, Blando, \& Bindon, 2019; Quijada-Morín, Williams, Rivas-Gonzalo, Doco, \& Escribano-Bailón, 2014; Springer, Sherwood, \& Sacks, 2016; Watrelot, Schulz, \& Kennedy, 2017).

It is known that proteins interact with tannins to form insoluble complexes, and this is exploited in fining treatments for example to remove the most reactive tannins from wines (Marangon, Vincenzi, \& Curioni, 2019). Also polysaccharides are able to bind to tannins, resulting for example in a diminished astringency perception in wine (Carvalho et al., 2006; McRae \& Kennedy, 2011; Riou, Vernhet, Doco, \& Moutounet, 2002; Watrelot et al., 2017).

Proteins in wines have been widely studied because they are the

\footnotetext{
* Corresponding author.

E-mail address: matteo.marangon@unipd.it (M. Marangon).
} 
culprit for the formation of protein haze during the storage of white wines (Van Sluyter et al., 2015). Conversely, proteins in red wines have not received the same level of attention, and only recently these proteins have been considered in the scientific literature (Bindon et al., 2016; Smith, Penner, Bennett, \& Bakalinsky, 2011; Sommer, Dickescheid, Harbertson, Fischer, \& Cohen, 2016). Proteins found in red wines are similar to those found in whites, being mainly constituted by the grape pathogenesis-related proteins (Mainente et al., 2014), which are found unvaried in all Vitis vinifera cultivars (Righetti \& D'Amato, 2017).

Red wines are produced with a maceration step that allows for the extraction of large quantities of phenolic compounds and macromolecules from the grape skins into the wine. Thus, at least in the past, the common idea was that all wine proteins would be precipitated with tannins during red winemaking, while nowadays it is understood that this is not the case. However, the role of proteins on red wine quality remains still largely unknown.

Despite their importance, red wine colloids have proven difficult to study. One technique that has been used in wine science is Dynamic Light Scattering (DLS) (Nguela, Poncet-Legrand, Sieczkowski, \& Vernhet, 2016; Pascal, Poncet-Legrand, Cabane, \& Vernhet, 2008; Poncet-Legrand, Cartalade, Putaux, Cheynier, \& Vernhet, 2003; Riou, Vernhet, Doco, \& Moutounet, 2002). DLS gives the possibility to gain information on the size of different colloids, but does not allow for their chemical characterization. Generally, the colloidal particle sizes are larger than those of wine proteins and polysaccharides, indicating that more than one macromolecular species must be present in the particles, whose dimensions may be modulated by different proportions of macromolecules. These proportions greatly depend on the maceration process during which the kinetics of extraction of these components are different, potentially resulting in differences in colloidal particles composition, size and reactivity, with consequences on wine stability and quality (Bindon et al., 2016). Therefore, the composition of the colloidal particles in red wines needs to be addressed and related to their sizes. To do that, given that colloidal aggregates in wine are likely to be stabilized also by weak interactions, these need to be purified with methods that preserve their native structure. This has been tentatively done by size exclusion chromatography (SEC) (Aron \& Kennedy, 2007; Le Bourvellec \& Renard, 2012; Watrelot et al., 2017). However, colloids separated by chromatography can interact with the stationary phases (Coelho et al., 2017), and can be de-structured as they are placed in physico-chemical conditions different from those of wine (Le Bourvellec \& Renard, 2012; Santos-Buelga \& de Freitas, 2009; Scollary, Pásti, Kállay, Blackman, \& Clark, 2012). Therefore other techniques need to be adopted, including Nanoparticle Tracking Analysis (NTA), a technique recently used to assess the hydrodynamic diameter and concentration of nanoparticles in liquids, that has been explored for the size analysis of simulated wine supramolecular structures. However, results have been obtained either by fractionating wine macromolecules and adding them back in a model system (reconstitution experiments), or by separating colloids from wines in harsh conditions likely to affect their structure (Bindon et al., 2016; Li, Wilkinson, Mierczynska-Vasilev, \& Bindon, 2019).

One of the techniques that can overcome the methodological issues mentioned above is Field Flow Fractionation (FFF), which is suitable for the characterization of nanosized and microsized systems (Roda et al., 2009). Among FFF sub-techniques, Asymmetrical Flow-Field Flow Fractionation (AF4), because of the lack of a stationary phase, offers a unique gentle separation mechanism able to avoid particle alteration (Contado, 2017; Giddings, 1993; Rigaux et al., 2017). In addition, AF4 shows a wide application range, both in terms of analytes' size and carrier fluid choice (Zattoni, Roda, Borghi, Marassi, \& Reschiglian, 2014). The separation is obtained by the application of a stream of carrier along an empty capillary channel together with an orthogonal, hydrodynamical flow. The two perpendicular flows are generated by splitting the longitudinal (pump delivered) flow into a second one (namely the cross-flow) across the permeable wall of the channel.
Particles' retention times are inversely proportional to their diffusion coefficient (D), and directly proportional to their hydrodynamic radius (Schimpf, Caldwell, \& Giddings, 2000). AF4 can be coupled online with a series of detectors (UV/Vis, fluorescence and multi-angle light scattering, MALS) to provide at the same time spectroscopic and size characterization, giving insights on the sample's composition, stability and aggregation/disaggregation phenomena (Marassi et al., 2018, 2015; Reschiglian et al., 2014; Zattoni et al., 2009).

MALS detection is an absolute method for particle sizing and molar mass determination in the $10 \mathrm{~nm}-1 \mu \mathrm{m}$ range without the need of any standard (Thielking, Roessner, \& Kulicke, 1995). Independently of the sample's concentration, nature, particle conformation or shape, MALS provides the root mean square (rms) radius, which represents the mass-averaged distance of each mass element of the particle from its center of gravity (gyration radius).

AF4 was widely used in hyphenation with different detection systems to characterize the macromolecular and colloidal fractions in different foods and ingredients (Nilsson, 2013 and references therein), while it has been used to study wine only once to fractionate white wine chromophoric colloids, which were then studied off-line by UV and fluorescence analysis (Coelho et al., 2017). However, the mobile phase composition used for the AF4 separation was very different from wine. Conversely, FFF techniques have never been applied to characterize red wine colloids. A major benefit of these techniques is the ability to work in physicochemical conditions similar to those of the starting wine, so to avoid colloid modifications during separation and analysis. By exploiting these advantages, the present study investigated, for the first time, the nature of the colloids present in two red wines by developing a novel method for the analysis and fractionation of colloids in native state by employing an AF4-multidetector platform equipped with UV, Fluorescence and Multi-Angle Light Scattering (MALS). Subsequently, the collected AF4-fractions were analyzed to elucidate their composition. Finally, a new model describing the structure and composition of red wine colloids is proposed.

\section{Materials and methods}

\subsection{Wine samples}

Two commercial red wines (vintage 2016) sourced from the Treviso Area (Veneto, Italy) and produced from $100 \%$ Raboso Piave grapes were used. The winemaking protocol did not include any filtration, oak contact, fining treatments, malolactic fermentation or ageing on yeast lees. Wines were clarified by settling and racking only, and were added with $50 \mathrm{mg} / \mathrm{L}$ of $\mathrm{SO}_{2}$ prior to bottling.

\subsection{Asymmetrical flow field-flow fractionation}

AF4 was performed using an Agilent 1100 system (Agilent Technologies, Palo Alto, CA) combined with an Eclipse 3 Separation System (Wyatt Technology Europe, Dernbach, Germany). The channel was 152 $\mathrm{mm}$ long, $16 \mathrm{~mm}$ wide, and $350 \mu \mathrm{m}$ thick. Regenerated cellulose membranes with $5 \mathrm{kDa}$ cut-off (Microdyn-Nadir, Wiesbaden, Germany) were used. An AF4 separation method is composed of four steps: focus, focus-injection, elution and elution-injection (Ratanathanawongs-Williams \& Giddings, 2000). During the focusing step, two opposite flows of carrier fluid confine the injected sample to a narrow band and make sample components reach their equilibrium position across the channel section. During the elution step, only one longitudinal flow is kept (detector flow) and a secondary, transversal flow (cross-flow) drives the separation mechanism. The cross-flow is released during the last step (elution-inject) where the injector is cleaned and the fully retained species are eluted. The channel outlet flow rate was set to $0.5 \mathrm{~mL} / \mathrm{min}$. The focusing step was performed for $1 \mathrm{~min}$ with a focusing flow rate of $2 \mathrm{~mL} / \mathrm{min}$ to equilibrate the flows and then for $8 \mathrm{~min}$ in focus-injection mode to allow for the complete sample injection and 
focusing. For the separation step, an initial cross-flow rate of $1.5 \mathrm{~mL} / \mathrm{min}$ was set, and then lowered to $0.00 \mathrm{~mL} / \mathrm{min}$ in $28 \mathrm{~min}$ using a linear gradient. The cross-flow rate was then maintained to $0.00 \mathrm{~mL} / \mathrm{min}$ in elution mode for $5 \mathrm{~min}$ to ensure complete elution of the largest aggregates (in the $90-300 \mathrm{~nm}$ range). The mobile phase was model wine (12.5\% ethanol (v/v), $2.5 \mathrm{~g} / \mathrm{L}$ L-tartaric acid adjusted to $\mathrm{pH} 3.5$ with $\mathrm{KOH})$. The software package Wyatt Eclipse @ ChemStation Version B.03.01 (Wyatt Technology Europe) was used to set and control the flow rate values. On-line detection of the eluted species was performed with an Agilent $1100 \mathrm{DAD}$ UV/Vis spectrophotometer, a multi angle light scattering (MALS) detector (MALS DAWN HELEOS, Wyatt Technology Corporation, Santa Barbara, CA) and a 1200 fluorescence detector (Agilent Corporation). Carrier solutions were degassed using an on-line vacuum degasser Agilent, 1100 series (Agilent Technologies). Prior to separation, the total colloidal content of wines A and B was evaluated with a Flow-Injection Analysis (FIA) and a Focus-FIA. A Flow Injection Analysis (FIA) is a shortened, non-separative method: the sample is injected into the channel in absence of cross/focus flow and it reaches the detector without separation. It allows evaluating the signal related to $100 \%$ recovery of sample. A Focus-FIA is a FIA with an added preliminary focusing step, where the sample is subject to the focus flow and narrowed in a thin band at the beginning of the channel. In FIA, the entirety of the sample reaches the detector, while in Focus-FIA the sample components smaller than the membrane cutoff are filtered out, and only the colloidal portion of the sample goes through the detector. The ratio between the areas under signal curve obtained in Focus-FIA and FIA (\% Focus-FIA/FIA) gives the relative contribution of colloidal matter to each detector signal. The ratio between the areas under the signal curves obtained during the Separation method and in Focus-FIA (\% Separation/Focus-FIA) gives the relative recovery of colloids after fractionation.

The detector flow and the focus flow were kept identical to the separation method. An injection volume of $100 \mu \mathrm{L}$ was employed for FIA and Focus-FIA analyses, while $400 \mu \mathrm{L}$ were injected for MALS characterization.

The separation method allowed for the collection of 12 fractions from both wines. For both wines four consecutive injections of $900 \mu \mathrm{L}$ were performed which gave identical results and resulting fractions (1.5 $\mathrm{mL}$ each) were collected and pooled prior to their characterization. The entire characterization and fractionation process was performed within the first $6 \mathrm{~h}$ from the opening of the bottles to avoid possible degradation phenomena upon exposure to air.

\subsection{Polysaccharides quantification}

The quantification of the total polysaccharides content of the two wines and of the collected fractions was performed by adapting the method proposed by Segarra et al. (Segarra, Lao, López-Tamames, \& De La Torre-Boronat, 1995). Briefly, wines were pre-treated with polyvinylpolypyrrolidone (PVPP, Polyclar, Ashland) at $5 \mathrm{mg} / \mathrm{mL}$ to remove interfering phenolic material. Wine samples were placed in an orbital shaker for one hour before separating the PVPP via centrifugation (3500 g, $5 \mathrm{~min}, 4^{\circ} \mathrm{C}$, Mikro 200, Hettich). The supernatants were filtered (0.45 $\mu \mathrm{m}, \mathrm{PES}$ syringe filters, Sartorius) and $20 \mu \mathrm{L}$ were added with $500 \mu \mathrm{L}$ of absolute ethanol (Sigma-Aldrich), stored at $4{ }^{\circ} \mathrm{C}$ for $16 \mathrm{~h}$ and centrifuged at $14000 \mathrm{~g}$ for $30 \mathrm{~min}$. The obtained pellets were dried by placing the open vials on a heating mantle set at $65^{\circ} \mathrm{C}$ for $30 \mathrm{~min}$. Pellets were then solubilized with $1 \mathrm{~mL}$ of a water/phenol solution prepared by dissolving phenol (Fluka) at $2 \%(\mathrm{v} / \mathrm{v})$ in distilled water. Then, $400 \mu \mathrm{L}$ of the samples were transferred into a new vial and added with $1 \mathrm{~mL}$ of pure sulphuric acid (Sigma-Aldrich). After $30 \mathrm{~min}$, the absorbance was measured at $490 \mathrm{~nm}$. A calibration curve was prepared using a serial dilution of glucose $(0-100 \mathrm{mg} / \mathrm{L}$, Sigma-Aldrich) prepared in the water/phenol solution. For quantification of polysaccharides in the AF4-fractions the same procedure was adopted except that these were not pre-treated with PVPP as most of the interfering phenolic material was supposed to be removed by the focusing step of the separation method. Additionally, the sample volume was $250 \mu \mathrm{L}$ that were precipitated with $1 \mathrm{~mL}$ of absolute ethanol.

\subsection{Protein quantification}

Protein content of wine fractions was evaluated by on-line measuring the fluorescence produced at $340 \mathrm{~nm}$ upon excitation at $280 \mathrm{~nm}$ during the separation method. Known quantities (10-80 $\mu \mathrm{g})$ of a standard protein (BSA, Sigma-Aldrich) were submitted to the same separation method to calibrate for protein quantification: fluorescence peak areas were plotted against injected amount and wine fluorescence areas were interpolated to obtain their relative protein correspondence.

\subsection{Phenolic quantification}

Phenolic content of wines and AF4-fractions was evaluated by the Folin-Ciocalteu (FC) method (Singleton, Orthofer, \& Lamuela-Raventós, 1999). Briefly, sample ( $200 \mu \mathrm{L})$ or blank (model wine alone) was mixed with FC reagent (Sigma-Aldrich) and $800 \mu \mathrm{L}$ of $\mathrm{Na}_{2} \mathrm{CO}_{3}(7.5 \% \mathrm{w} / \mathrm{v})$. After $30 \mathrm{~min}$ of incubation at $40{ }^{\circ} \mathrm{C}$, the absorbance was measured at $725 \mathrm{~nm}$ in a spectrophotometer (PerkinElmer $\lambda$ 1A UV-VIS). A calibration curve was prepared using gallic acid solution (Sigma-Aldrich) in a concentration range between 0.025 and $0.2 \mathrm{mg} / \mathrm{mL}$.

\subsection{Sodium Dodecyl sulfate-polyacrylamide gel electrophoresis (SDS-} PAGE)

AF4-fractions were analyzed by SDS-PAGE according to Laemmli (Laemmli, 1970). Briefly, $500 \mu \mathrm{L}$ of AF4-fractions were dialyzed against water (3.5 kDa MWCO) and freeze dried before being dissolved in $25 \mu \mathrm{L}$ Laemmli Sample Buffer (Bio-Rad Laboratories, Hercules, CA, USA) prepared with 5\% 2-mercaptoethanol as reducing agent. Samples were then heated at $95{ }^{\circ} \mathrm{C}$ in a dry bath (H2O3-100C, Coyote Bioscience Co., Beijing, China) for $5 \mathrm{~min}$. Then, $10 \mu \mathrm{L}$ of each sample were loaded on Mini-Protean TGX stain free precast gels 8-16\% (Bio-Rad Laboratories). Precision Plus Protein Standards broad range (range 10-250 kDa, Bio-Rad Laboratories) were used. Proteins were stained by using the Silver stain procedure (Blum, Beier, \& Gross, 1987) and periodic Acid-Schiff (PAS) for glycoprotein quantification (Doerner \& White, 1990). Images of the gels were acquired at 300 dpi resolution with a ChemiDoc $^{\mathrm{TM}}$ XRS molecular imager (Bio-Rad Laboratories).

\section{Results and discussion}

In a preliminary study the concentration of proteins, polysaccharides and phenolics of 111 dry red wines was measured (data not shown). These wines were produced with a winemaking protocol aimed at preserving their colloidal status (e.g. lack of filtration, oak contact, fining treatments, malolactic fermentation, and ageing on yeast lees). From this survey, two wines of the same variety (cv, Raboso Piave, named A and $B$ ) showing different values, but within the range representative for this variety, were selected.

Wines were submitted to AF4 analysis and online multidetection to detect the differences between the two in terms of colloidal content, and characterize colloids in terms of spectroscopical properties and size. Subsequently, both wines were fractionated and the resulting fractions analyzed to elucidate their content in colloid-forming molecules, namely proteins, polysaccharides and phenolics.

\subsection{Wine colloids fractionation by AF4}

The AF4 approach was initially used to highlight the differences between the whole colloidal content of the two wines, and then to characterize it in terms of size and absorbance properties. To do so, both wines were directly analyzed with three different FIA, Focus-FIA and 
Separation method. Absorbances of the eluting material were measured at the three wavelength (at 235, 280 and $515 \mathrm{~nm}$ ) corresponding to the three maxima of absorption visible in the 3D spectrum (Fig. 1).

Initially, FIA and focus-FIA analyses were performed to isolate the total wine colloidal material and to estimate its abundance. Whereas the FIA analysis showed very high and similar absorption for both wines, the signal decreased when the same amount of sample was analyzed by Focus-FIA, (not shown), thus indicating that the non-colloidal portion of the wine has been removed by the focusing step which acted as filtration (5 kDa cut-off membrane). While the absorption after FIA were similar for the two wines, those after Focus-FIA, albeit the same amount was injected for both wines, greatly differed, being higher for wine B. In order to gain information on the relative reduction of the species absorbing at different wavelengths caused by the focusing step, the percentage ratios between the peak areas obtained with Focus-FIA and those obtained with FIA (all species) at 280 and $515 \mathrm{~nm}$ were calculated (Table 1).

Assuming that the composition of the colloidal fraction of the two wines was similar, results showed that absorbing species of wine $\mathrm{B}$ contained a higher percentage of material larger than $5 \mathrm{kDa}$ than wine $\mathrm{A}$. However the decrease in absorption was not the same for all wavelengths (Table 1), thus indicating compositional differences between the two wines. These results could be attributed to the vinification process, and in particular to pre-fermentative and maceration practices that can result in a different extraction of macromolecules (Gil et al., 2012; Smith, McRae, \& Bindon, 2015).

The highest loss of signal, particularly for wine A, was at $280 \mathrm{~nm}$, where proteins and phenolics absorb. Given that proteins are larger than the membrane cut-off, it is likely that this loss was due to the passing through the membrane of phenolics not bound to macromolecules. Therefore, the Focus-FIA Absorption at $280 \mathrm{~nm}$ should be due to the presence of proteins and/or phenolics, either large and in free form (e.g. polymeric tannins), or bound to large molecules (e.g. proteins or polysaccharides) (Waterhouse et al., 2016). Therefore, the focusing step is essential in order to be able to analyze the chemical identity of wine colloids without the interference of other molecules.

\subsection{Size characterization}

Wine A and B colloids were size-characterized by laser scattering (light scattering signal at $90^{\circ}$; LS) using a multi-angle light scattering (MALS). Interestingly, although a single peak is visible in absorption (Fig. 2, blue and red thin lines), three distinct peaks are detected by LS indicating that different populations coexist in the colloidal fraction (Fig. 2, solid lines).

The first species observed, corresponding to the absorption fractogram maximum (first LS peak), shows the same gyration radius $(32 \mathrm{~nm})$
Table 1

Colloidal contribution to the absorbance (in \%), and colloids' recovery (in \%) of the separation method for wines $\mathrm{A}$ and $\mathrm{B}$.

\begin{tabular}{clll}
\hline & $\begin{array}{l}\text { Wavelength } \\
(\mathrm{nm})\end{array}$ & $\begin{array}{l}\text { Colloids contribution to } \\
\text { absorbance (\% Focus-FIA/FIA) }\end{array}$ & $\begin{array}{l}\text { Colloids recovery } \\
\text { (\% Separation/ } \\
\text { Focus-FIA) }\end{array}$ \\
\hline Wine & 280 & 8 & 90 \\
A & 515 & 14 & 89 \\
Wine & 280 & 28 & 89 \\
B & 515 & 29 & 89 \\
\hline
\end{tabular}

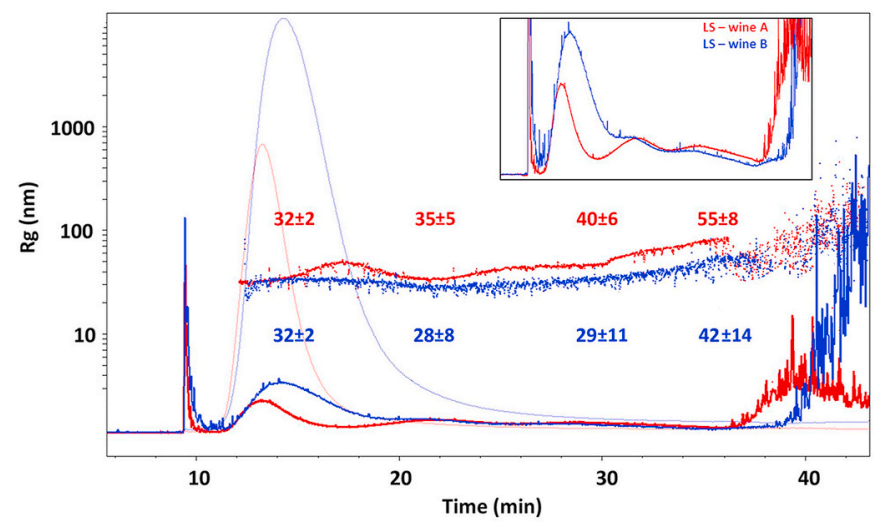

Fig. 2. Sizing of wine A (red) and wine B (blue) colloids. Errors are given as standard deviation of the signal over 1 min elution time. The differences in gyration radius $(\mathrm{Rg})$ values observed at retention time higher than $20 \mathrm{~min}$ are always significant at $99 \%$ confidence ( $t$-test, $\mathrm{P}<0.0015)$. Solid lines: LS @ $90^{\circ}$; thin lines: absorption @280 nm; dotted distribution: Rg. Numbers: radius' values for the three LS peaks and at the time cross-flow release (37 min). Insert: zoom of the LS signals to highlight peaks. (For interpretation of the references to color in this figure legend, the reader is referred to the Web version of this article.)

for both wines. However, from this point onwards the gyration radius measured for the two wines diverge to reach the maximum difference. Indeed, the differences in gyration radius values observed at retention times higher than 20 min were always significant $(P<0.0015)$. At the cross-flow release (min 37), both wines display a very low amount of large aggregates (up to $90 \mathrm{~nm}$ ) (Fig. 2). Gyration radii values for wine A are higher than for wine $\mathrm{B}$, suggesting different arrangements of the species constituting the colloids. Indeed, the different values calculated for wines A and B after 20 min of separation suggest that species with the same retention time (hence the same hydrodynamic radius) may have different mass distribution in colloidal particles. Such a difference can be
Wine A

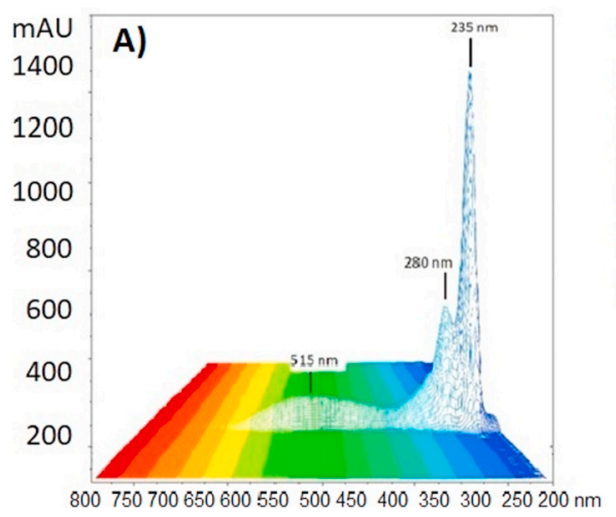

Wine B

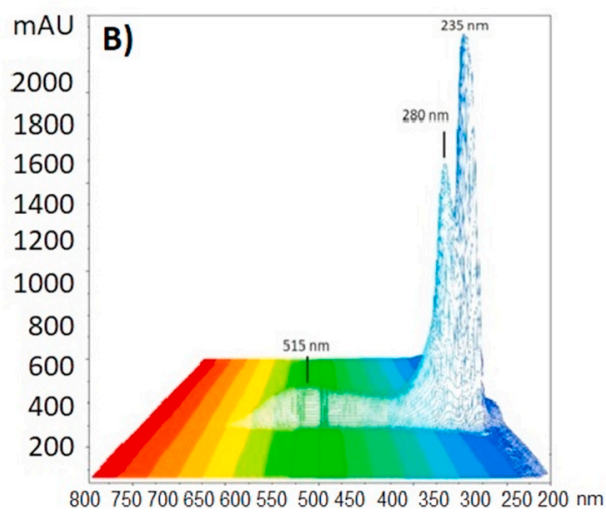

Fig. 1. 3D absorption spectra $(800-200 \mathrm{~nm})$ of the colloids of wines A and B. 
due either to a different density or to a different shape of the colloids of the two wines, but based on the here reported data it is not possible to elucidate this point further.

\subsection{Chemical characterization of AF4-fractions}

The separation method was used to fractionate the wines into 12 fractions, which were collected along the entire fractogram. For both wines, four consecutive injections were performed which gave identical results (fractograms not shown) allowing for the corresponding fractions to be pooled.

In order to understand the composition of the colloids differing in size, the quantities of proteins, polysaccharides and phenolics present in the AF4-fractions were measured (Fig. 3). Protein content in the unfractionated wines and AF4-fractions was measured by fluorimetry because both UV absorption of wine colloidal particles and most of the colorimetric methods (e.g. Bradford) would be affected by the presence of phenolics. One issue could be the fluorescence quenching induced by polyphenols bound to proteins (Soares, Mateus, \& de Freitas, 2007), but the same risk arises when using other conventional quantification methods.

The quantification of proteins, polysaccharides and phenolics in the AF4-fractions with different gyration radii showed very different amounts of these components, which differed also between the corresponding fractions of the two wines (Fig. 3C and D).

The concentration of proteins and phenolics in the 12 consecutive fractions follow the same trend of the fractogram obtained during the separation method (see Fig. 3A and B).

The total amount of phenolics recovered in the 12 fractions (139.8 $\mathrm{mg} / \mathrm{L}$ for wine A and $607.5 \mathrm{mg} / \mathrm{L}$ for wine B) is much lower than those of the starting wines $(1219.8 \pm 147.7 \mathrm{mg} / \mathrm{L}$ for wine $\mathrm{A}$ and $1852.1 \pm 114.5$ $\mathrm{mg} / \mathrm{L}$ for wine $\mathrm{B}$ ), indicating that most of the phenolics were removed by the AF4 filtration step as they should be sufficiently small to pass through the AF4 membrane. Nevertheless, certain amounts of phenolics are found in the AF4-fractions (Fig. 3C and D), and therefore they must be present in an aggregated or polymeric state. Indeed, high molecular weight phenolic compounds are produced in wine through polymerization involving procyanidins and anthocyanins to form the so-called polymeric pigments (Kennedy, Saucier, \& Glories, 2006; ). Results of Fig. 3 confirm this as both wines showed absorption at $515 \mathrm{~nm}$, indicating the presence of anthocyanins (which when in free form are smaller than the filtration membrane used) in the AF4-fractions (see Fig. 3A and B). However, the fact that phenolics are found in the same AF4-fractions in which proteins can be detected (Fig. 3C and D) suggests that these two species are associated to form colloidal particles. This can be expected because of the well-known ability of tannins to bind proteins, as previously shown for wine by using recombination/reconstitution experiments with grape tannins and model (de Freitas, Carvalho, \& Mateus, 2003) or real (Gazzola, Van Sluyter, Curioni, Waters, \& Marangon, 2012) wine proteins.

Despite the limitations of the methods of quantification used that can be affected by interferences between the two measured species, the phenolics/proteins ratio of F2, the fraction corresponding to the first LSpeak, in wine $\mathrm{A}$ (ratio $\approx 4$ ) seems to be more than double of that of wine $\mathrm{B}$ (ratio $\approx 1.7$, see Fig. 3 C and D). Even tough wine B only had $30 \%$ more total phenolics than wine A, after fractionation only $15 \%$ of the initial quantity of phenolics was retrieved for wine A, while for wine B the recovery was more than double (33\%). This situation could be due to the presence of polysaccharides that, in fact, are present in higher quantity in wine A (discussed below). As shown by previous studies, polysaccharides can modulate the aggregation between proteins and phenolics (de Freitas, Carvalho, \& Mateus, 2003), probably by binding phenolics that are no longer available to interact with proteins (Riou, Vernhet, Doco, \& Moutounet, 2002).

Given that polysaccharides are known to participate in the formation of colloidal particles in wines (Martínez-Lapuente, Guadalupe, \& Ayestarán, 2019), their quantities was measured on both the AF4-fractions (Fig. 3) and the starting wines. Generally, fractions from wine A contained more polysaccharides than those from wine B. This finding is supported by the measure of total polysaccharides in the
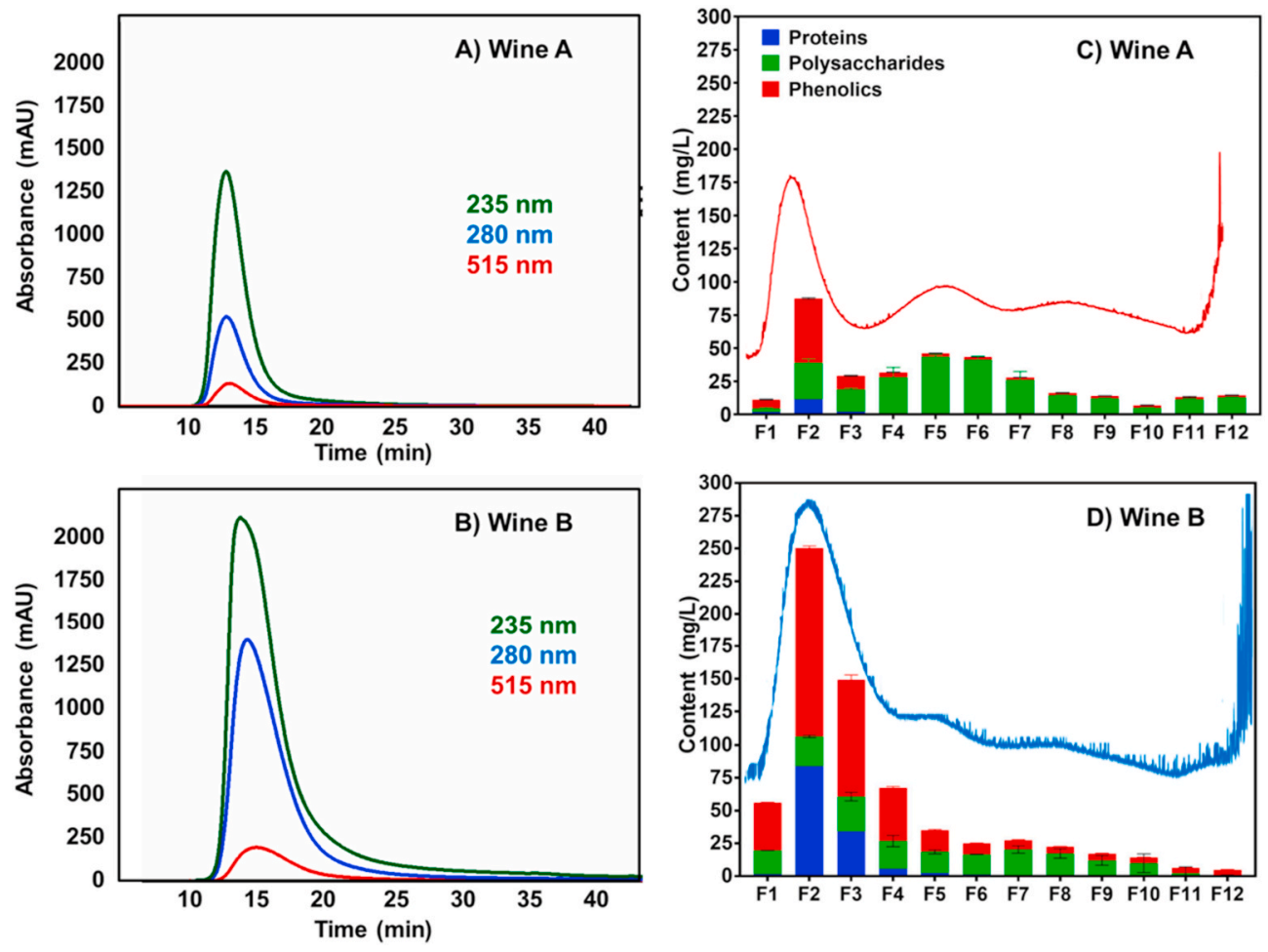

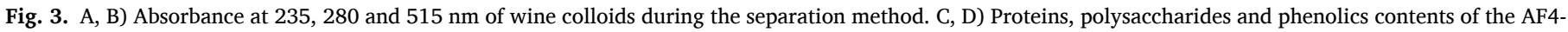
fractions. Lines indicate LS @ $90^{\circ}$. 
unfractionated wines by colorimetric analysis $(426.6 \mathrm{mg} / \mathrm{L}$ for wine A and $305.0 \mathrm{mg} / \mathrm{L}$ for wine B). By comparing these values with those obtained by summing the content found in the individual AF4-fractions ( $403.2 \mathrm{mg} / \mathrm{L}$ for wine A and $299.8 \mathrm{mg} / \mathrm{L}$ for wine B) it is possible to assume that no polysaccharides with a molecular weight lower than that of the filtration membrane used ( $5 \mathrm{kDa}$ ) were present in the original wine.

Wine polysaccharides can behave as colloids by themselves, but it is more likely that they are associated with other colloid-forming particles as proteins and/or phenolics (Bindon et al., 2016). Nevertheless, the polysaccharides' content seems to be not related to the amount of proteins and phenolics present in the AF4-fractions. Indeed, unlike what observed for proteins and phenolics, measurable amounts of polysaccharides are present in almost all fractions for both wines, with the highest quantities in F5 and F6 for wine A and in F3 for wine B (Fig. 3). This could be because polysaccharides can be present either in free form or associated to colloidal particles made of proteins and phenolics. However, considering the size of polysaccharides, finding them in fractions containing colloidal particles with different dimensions suggests that they are associated with other molecules. Interestingly, in wine A the proteins, polysaccharides and phenolics peak in the same fraction (F2), which contained more polysaccharides than proteins, while the situation for wine $B$ is different. This corresponds to a different protein/phenolic ratio, a fact indicating that the polysaccharides are responsible for modulating this ratio by interacting with the phenolics (Le Bourvellec \& Renard, 2012).

In order to confirm the assumption that proteins and phenolics are associated in the colloidal particles, and to compare the sizes found with the AF4 technique in native conditions (Fig. 2) to those resulting from the denaturing electrophoretic analysis, AF4-fractions were submitted to electrophoretic separation using wine $\mathrm{A}$ as representative sample (Fig. 4).

By SDS-PAGE, smearing bands reactive to the stain used for protein detection were visible in the first 7 AF4-fractions (Fig. 4A). The gel confirmed results of Fig. 3, as F2 was the fraction with the more intense. The following fractions show faint bands with intensity that gradually decreases until no noticeable signal was present from F8 to F12. When
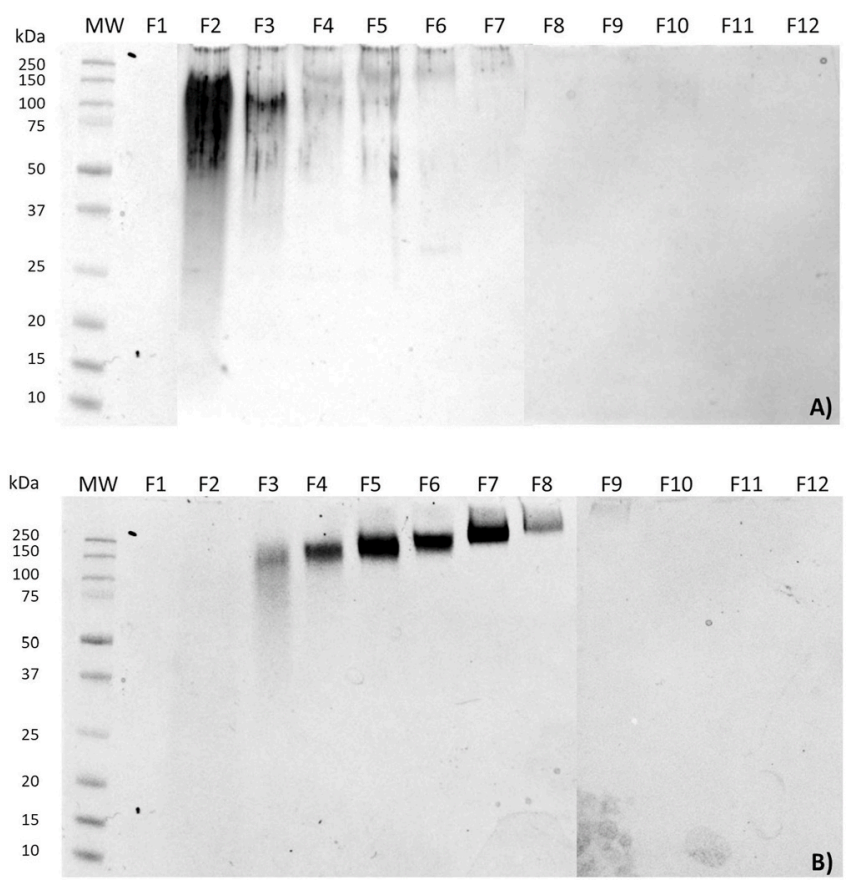

Fig. 4. SDS-PAGE analysis in reducing conditions of the 12 AF4-fractions of wine A. A) Silver staining for protein detection; B) PAS staining for sugar detection. MW, molecular weight standard proteins. looking at the gel stained for sugars (Fig. 4B), bands appeared in F3 until F8, and their mobility corresponded to that of the faint bands detected by silver stain (Fig. 4A), suggesting the presence of both sugars and proteins in the same band. These compounds are likely to be the mannoproteins (Vincenzi, Marangon, Tolin, \& Curioni, 2011), a class of polysaccharides made of mannose (about $90 \%$ ) and a small percentage of protein (about 10\%) released by yeast during fermentation and autolysis (Goncalves, Heyraud, Norberta de Pinto, \& Rinaudo, 2002). So, proteins are mostly visible in the first fractions (F2-F3), while mannoproteins seem to be the main constituent in the following fractions (F4-F8). Interestingly, despite the presence of polysaccharides in F2 (see Fig. 3), no PAS-stained material can be seen in this fraction. This suggests that polysaccharides different from mannoproteins, as the grape-derived rhamnogalacturonans II (RGII) or polysaccharides rich in arabinose and galactose (PrAGs), which are unable to enter the gel, can be present in this fraction even if their presence also in the other fractions cannot be excluded.

The position in the gel of the silver stained material of F2 and F3 corresponds to an apparent MW that is 4-fold higher (100-150 kDa) than that of red wine proteins, which were found at around $25-30 \mathrm{kDa}$ (Mainente et al., 2014). This shows that the proteins of the AF4-fractions are in an aggregated state that partially impairs their electrophoretic mobility. Moreover, the stained material is mostly visible as smears, and this is likely due to the presence of protein/phenolics complexes, a well-known occurrence in plant-derived samples (Czubinski \& Dwiecki, 2017). In these complexes, the interaction between proteins and phenolics must be stabilized by strong chemical bonds as the denaturing conditions used in SDS-PAGE are not sufficient to break them. Indeed, the formation of irreversible covalent bonds between proteins and phenolics can occur mainly due to reactive species deriving from the oxidation of phenolic compounds (Le Bourvellec \& Renard, 2012).

In contrast, the PAS-stained bands are well defined, and no smear is visible in the corresponding silver stained bands, indicating that mannoproteins are not covalently bound to phenolics that, however, are present in the fractions as they can be quantified colorimetrically (see Fig. 3). In this case, it can be hypothesized that the interaction between phenolics and mannoproteins can be disrupted by the denaturing conditions of the electrophoresis.

The apparent molecular mass of the species detected by electrophoresis (Fig. 4) is not matching the sizes of the colloidal aggregates as measured by MALS (see Fig. 2). This indicates that wine colloidal particles present in AF4-fractions were partially degraded to smaller subunits (protein-phenolics aggregates) or components (mannoproteins) by the strong denaturing conditions applied for SDS-PAGE sample preparation. This means that other types of non-covalent interactions (e. g. hydrogen bonds and hydrophobic interactions) occur in the native wine colloidal particles (Le Bourvellec \& Renard, 2012), which should include the covalently-bound sub-units visualized by SDS-PAGE or mannoproteins (Fig. 4).

\subsection{Hypothetical mechanism for colloidal aggregation in red wines}

Considering the portion of the fractograms where most of the colloidal material is found (see peak in Fig. 3), and also what can be found in the literature (Mateus, Carvalho, Luís, \& de Freitas, 2004), the above discussed results can be used to propose a hypothetical mechanism for colloid formation in red wine that is dependent on the ratio between different classes of colloid-forming molecules and the type of bond they form.

It is proposed that the aggregation among proteins, polysaccharides and phenolics results from the combination of two processes. Initially covalently linked aggregates between proteins and phenolics form, resulting in the production of sub-aggregates (Fig. 5A). These subaggregates are those visible by SDS-PAGE, in which no free proteins were found (see Fig. 4A), suggesting that all proteins in red wines are strongly bound to phenolics, a finding in line with results reported by 


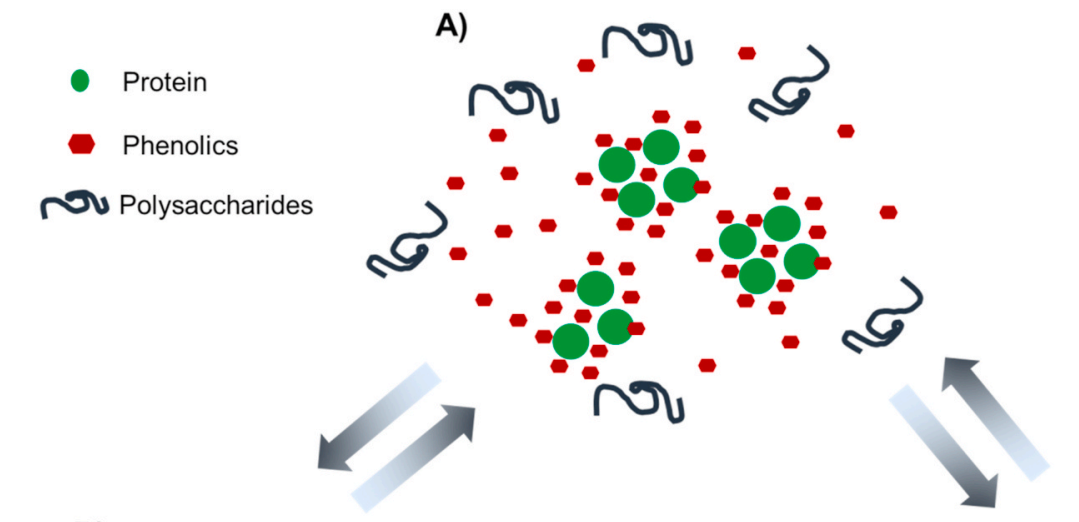

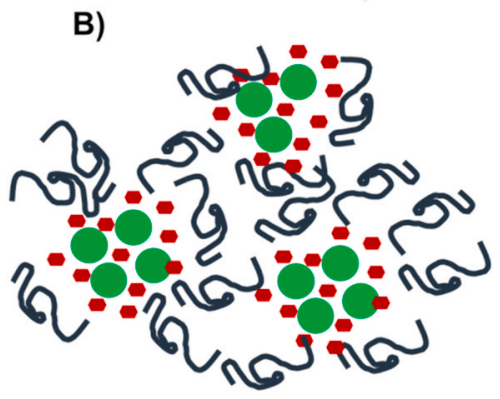

Aggregates found in F1-F3

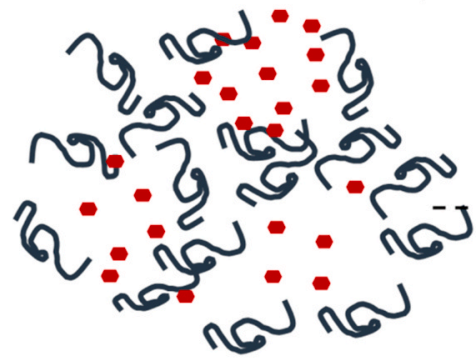

Aggregates found in F5-F12

Fig. 5. Proposed mechanisms for colloidal aggregation in red wine. A) Covalently linked protein-phenolics sub-aggregates and free polysaccharides and phenolics; B) Aggregates with low gyration radius (more compact); C) Aggregates with high gyration radius (less compact).

others (Wigand, Tenzer, Schild, \& Decker, 2009). The second process should be a further aggregation step where aggregates grow through interaction among covalently linked sub-aggregates and polysaccharides via non-covalent forces to form particles that, thanks to the presence of polysaccharides, remain stable in a colloidal dispersion (Fig. 5B). This interpretation is in line with one of the scenarios proposed by Mateus and colleagues, who suggested that a ternary complex protein-polyphenol-polysaccharide can form in wine thus enhancing its solubility in aqueous medium (Mateus et al., 2004). This should be the case for the particles found in the first fractions (F1 to F3).

In addition, on the basis of the here-presented findings (see Figs. 3 and 4), an alternative type of aggregates should be present in red wines, being formed by only phenolics and polysaccharides (see Fig. 5C), a possibility already hypothesized by Mateus and colleagues (Mateus et al., 2004). This should be the case for the particles found in the later eluting fractions (F4 to F12).

In summary, at least in the red wines tested, all the proteins seem to be involved in the colloidal aggregation (Fig. 5B), but the so formed aggregates can be accompanied by others in which proteins are absent (Fig. 5C). These two types of aggregates show different gyration radii (see Fig. 2), a parameter that can be seen as a proxy for their compactness. Indeed, the largest colloidal particles containing only polysaccharides and phenolics (see Figs. 3, 4 and 5C) should be less compact than those containing also proteins (see Fig. 5B). In this view, it is likely that the formation of different colloidal particles depends on the quantities and relative proportions of the individual components present in the wine, which can explain the differences between the two wines analyzed here.

\section{Conclusions}

Despite its fundamental relevance in enology, the study of colloidal interactions in red wines is still largely unexplored mostly because of the technical difficulties encountered for their analysis. These particles tend to easily change, and depending on their size and on the matrix they are in, they are very challenging to separate while maintaining the same native conditions in which they exist in wines. Indeed, the hypotheses formulated to explain the colloidal behavior of wine generally come from reconstitution experiments conducted in model systems using different combinations of proteins, polysaccharides and phenolic compounds, using molecules often different from those found in wine. Despite this approach has merit, it also has limitations for the study of wine colloids as they are in real wine conditions.

The best solution would be to study real wine colloids directly, but due to the technical difficulties, little information is available in the literature on this point, also in relation to the grape characteristics and vinification methods.

In this context, the use of AF4 combined with multiple detectors proved to be an appropriate method to fractionate, quantify and characterize native wine colloids. The AF4-approach indicated that wine colloidal particles are made of aggregates of proteins, polysaccharides and phenolics. The obtained results allowed to hypothesize that the structure of red wine colloids includes a central nucleus constituted by proteins covalently bound to phenolics interacting via non-covalent forces with polysaccharides that should contribute to maintain these aggregates in a stable colloidal state. This situation could explain the different behavior of proteins in red and white wines. In white wines, containing low quantities of polysaccharides, colloidal interactions can occur leading to aggregates' growth and eventually to haze formation (Dufrechou, Doco, Poncet-Legrand, Sauvage, \& Vernhet, 2015). Conversely, red wines, despite containing a much larger quantity of phenolics, thus being more exposed to their effects on proteins aggregation (Riou, Vernhet, Doco, \& Moutounet, 2002), are also richer in polysaccharides, and this should be the reason for their higher protein stability, as previously reported using model systems (Riou et al., 2002). One possible explanation is that polysaccharides could block the growth of the proteins/phenolics aggregates and/or increase the hydrophilicity of the particles thus favoring steric repulsion among them (López-Esparza, Balderas Altamirano, Pérez, \& Gama Goicochea, 2015). This type of stable ternary complex was indeed observed experimentally in this study. However, a different type of colloid was also found, essentially made of polysaccharides (including MPs) bound to small 
amounts of phenolics, confirming that these two classes of compounds can interact to form soluble particles as demonstrated in model systems (Riou et al., 2002). This type of colloid should be further investigated as should be the nature of the polysaccharides involved, which could originate from grapes and/or yeasts.

Generally, the results indicate that different wines can contain particles differing in terms of quantity, composition and dimension. What is causing these differences is still largely unknown, as unknown are the effects of ageing and storage conditions, but the results here presented indicate that the quantity and proportion of proteins, polysaccharides and phenolics play a key role.

Wine is subjected to a large number of variables including differences in vinification techniques (e.g. length of maceration, clarification, filtration, stabilization) known to impact directly or indirectly the quantity of proteins, polysaccharides and phenolics (Guadalupe \& Ayestaran, 2007). As a result, the characteristics of wine colloids can be greatly influenced by these practices, and therefore their impact needs to be investigated. In this context, the here proposed AF4-technique can be a valid method to increase our understanding of the colloidal behavior of wines.

\section{CRediT authorship contribution statement}

Valentina Marassi: Conceptualization, Data curation, Formal analysis, Investigation, Methodology, Project administration, Software, Supervision, Validation, Visualization, Writing - original draft, Writing review \& editing. Matteo Marangon: Conceptualization, Data curation, Formal analysis, Investigation, Methodology, Software, Supervision, Visualization, Writing - original draft, Writing - review \& editing. Andrea Zattoni: Conceptualization, Formal analysis, Funding acquisition, Methodology, Project administration, Resources, Supervision, Writing - review \& editing. Simone Vincenzi: Funding acquisition, Resources, Supervision, Writing - review \& editing. Andrea Versari: Conceptualization, Funding acquisition, Project administration, Resources, Writing - review \& editing. Pierluigi Reschiglian: Conceptualization, Funding acquisition, Project administration, Resources, Writing - review \& editing. Barbara Roda: Conceptualization, Funding acquisition, Methodology, Project administration, Resources, Supervision, Validation, Writing - review \& editing. Andrea Curioni: Conceptualization, Formal analysis, Funding acquisition, Project administration, Resources, Writing - review \& editing.

\section{Declaration of competing interest}

Andrea Zattoni, Barbara Roda, Pierluigi Reschiglian and Valentina Marassi are associates of the academic spinoff company byFlow Srl (Bologna, Italy). The company mission includes know-how transfer, development, and application of novel technologies and methodologies for the analysis and characterization of samples of nanobiotechnological interest.

\section{Acknowledgements}

This project was supported financially by the University of Padova, grant number DOR1953329/19, and by the Italian Ministry of Education, Universities and Research (MIUR), project N. 20157RN44Y. Mara Vegro and Pietro Ciriani (University of Padova) are thanked for their technical assistance.

\section{Appendix A. Supplementary data}

Supplementary data to this article can be found online at https://doi. org/10.1016/j.foodhyd.2020.106204.

\section{References}

Aron, P. M., \& Kennedy, J. A. (2007). Compositional investigation of phenolic polymers isolated from Vitis vinifera L. Cv. Pinot noir during fermentation. Journal of Agricultural and Food Chemistry, 55(14), 5670-5680. https://doi.org/10.1021/ jf0704817.

Bindon, K. A., Carew, A. L., Mierczynska-Vasilev, A., Kassara, S., Kerslake, F., \& Smith, P. A. (2016). Characterization of macromolecular complexes in red wine: Composition, molecular mass distribution and particle size. Food Chemistry, 199, 838-846. https://doi.org/10.1016/J.FOODCHEM.2015.12.079.

Blum, H., Beier, H., \& Gross, H. J. (1987). Improved silver staining of plant proteins, RNA and DNA in polyacrylamide gels. Electrophoresis, 8(2), 93-99. https://doi.org/ 10.1002/elps.1150080203.

Carvalho, E., Mateus, N., Plet, B., Pianet, I., Dufourc, E., \& de Freitas, V. (2006). Influence of wine pectic polysaccharides on the interactions between condensed tannins and salivary proteins. Journal of Agricultural and Food Chemistry, 54(23), 8936-8944. https://doi.org/10.1021/jf061835h.

Coelho, C., Parot, J., Gonsior, M., Nikolantonaki, M., Schmitt-Kopplin, P., Parlanti, E., et al. (2017). Asymmetrical flow field-flow fractionation of white wine chromophoric colloidal matter. Analytical and Bioanalytical Chemistry, 409(10), 2757-2766. https://doi.org/10.1007/s00216-017-0221-1.

Contado, C. (2017). Field flow fractionation techniques to explore the "nano-world. Analytical and Bioanalytical Chemistry, 409(10), 2501-2518. https://doi.org/ 10.1007/s00216-017-0180-6.

Czubinski, J., \& Dwiecki, K. (2017). A review of methods used for investigation of protein-phenolic compound interactions. International Journal of Food Science and Technology, 52(3), 573-585. https://doi.org/10.1111/ijfs.13339.

de Freitas, V., Carvalho, E., \& Mateus, N. (2003). Study of carbohydrate influence on protein-tannin aggregation by nephelometry. Food Chemistry, 81(4), 503-509. https://doi.org/10.1016/S0308-8146(02)00479-X.

Del Barrio-Galán, R., Medel-Marabolí, M., \& Peña-Neira, Á. (2015). Effect of different aging techniques on the polysaccharide and phenolic composition and sensory characteristics of Syrah red wines fermented using different yeast strains. Food Chemistry, 179, 116-126. https://doi.org/10.1016/j.foodchem.2015.01.075.

Doerner, K. C., \& White, B. A. (1990). Detection of glycoproteins separated by nondenaturing polyacrylamide gel electrophoresis using the periodic acid-Schiff stain. Analytical Biochemistry, 187(1), 147-150. https://doi.org/10.1016/0003-2697 (90)90433-A.

Dufrechou, M., Doco, T., Poncet-Legrand, C., Sauvage, F. X., \& Vernhet, A. (2015). Protein/polysaccharide interactions and their impact on haze formation in white wines. Journal of Agricultural and Food Chemistry, 63(45), 10042-10053. https://doi. org/10.1021/acs.jafc.5b02546.

Gazzola, D., Van Sluyter, S. C., Curioni, A., Waters, E. J., \& Marangon, M. (2012). Roles of proteins, polysaccharides, and phenolics in haze formation in white wine via reconstitution experiments. Journal of Agricultural and Food Chemistry, 60(42), 10666-10673. https://doi.org/10.1021/jf302916n.

Giddings, J. C. (1993). Field-flow fractionation: Analysis of macromolecular, colloidal, and particulate materials. Science, 260(5113), 1456-1465. https://doi.org/10.1126/ science. 8502990

Gil, M., Kontoudakis, N., González, E., Esteruelas, M., Fort, F., Canals, J. M., et al. (2012). Influence of grape maturity and maceration length on color, polyphenolic composition, and polysaccharide content of Cabernet sauvignon and Tempranillo wines. Journal of Agricultural and Food Chemistry, 60(32), 7988-8001. https://doi. org $/ 10.1021 /$ jf 302064 n.

Goncalves, F., Heyraud, A., Norberta de Pinto, M., \& Rinaudo, M. (2002). Characterization of white wine mannoproteins. Journal of Agricultural and Food Chemistry, 50(21), 6097-6101. https://doi.org/10.1021/jf0202741.

Guadalupe, Z., \& Ayestaran, B. (2007). Polysaccharide profile and content during the vinification and aging of Tempranillo red wines. Journal of Agricultural and Food Chemistry, 55(26), 10720-10728. https://doi.org/10.1021/jf0716782.

Kassara, S., Li, S., Smith, P., Blando, F., \& Bindon, K. (2019). Pectolytic enzyme reduces the concentration of colloidal particles in wine due to changes in polysaccharide structure and aggregation properties. International Journal of Biological Macromolecules, 140, 546-555. https://doi.org/10.1016/j.ijbiomac.2019.08.043.

Kennedy, J. A., Saucier, C., \& Glories, Y. (2006). Grape and wine phenolics: History and perspective. American Journal of Enology and Viticulture, 57(3), 239-248. Retrieved from https://www.ajevonline.org/content/57/3/239.

Laemmli, U. K. (1970). Cleavage of structural proteins during the assembly of the head of bacteriophage T4. Nature, 227(5259), 680-685. https://doi.org/10.1038/227680a0.

Le Bourvellec, C., \& Renard, C. M. G. C. (2012). Interactions between polyphenols and macromolecules: Quantification methods and mechanisms. Critical Reviews in Food Science and Nutrition, 52(3), 213-248. https://doi.org/10.1080/ 10408398.2010.499808.

Li, S., Wilkinson, K. L., Mierczynska-Vasilev, A., \& Bindon, K. A. (2019). Applying nanoparticle tracking analysis to characterize the polydispersity of aggregates resulting from tannin-polysaccharide interactions in wine-like media. Molecules, 24 (11). https://doi.org/10.3390/molecules24112100.

López-Esparza, R, Balderas Altamirano, M. A., Pérez, E., \& Gama Goicochea, A. (2015). Importance of molecular interactions in colloidal dispersions. Advances in Condensed Matter Physics. , Article 683716. https://doi.org/10.1155/2015/683716. https://www.hindawi.com/journals/acmp/2015/683716/.

Mainente, F., Zoccatelli, G., Lorenzini, M., Cecconi, D., Vincenzi, S., Rizzi, C., et al. (2014). Red wine proteins: Two dimensional (2-D) electrophoresis and mass spectrometry analysis. Food Chemistry, 164, 413-417. https://doi.org/10.1016/j. foodchem.2014.05.051. 
Marangon, M., Vincenzi, S., \& Curioni, A. (2019). Wine fining with plant proteins. Molecules, 24(11), 2186. https://doi.org/10.3390/molecules24112186.

Marassi, V., Casolari, S., Roda, B., Zattoni, A., Reschiglian, P., Panzavolta, S., ... Costa, A. L. (2015). Hollow-fiber flow field-flow fractionation and multi-angle light scattering investigation of the size, shape and metal-release of silver nanoparticles in aqueous medium for nano-risk assessment. Journal of Pharmaceutical and Biomedical Analysis, 106, 92-99. https://doi.org/10.1016/j.jpba.2014.11.031.

Marassi, V., Roda, B., Casolari, S., Ortelli, S., Blosi, M., Zattoni, A., ... Reschiglian, P. (2018). Hollow-fiber flow field-flow fractionation and multi-angle light scattering as a new analytical solution for quality control in pharmaceutical nanotechnology. Microchemical Journal, 136, 149-156. https://doi.org/10.1016/j. microc.2016.12.015

Martínez-Lapuente, L., Guadalupe, Z., \& Ayestarán, B. (2019). Properties of wine polysaccharides. In M. Masuelli (Ed.), Pectins - extraction, purification, characterization and applications. IntechOpen.

Mateus, N., Carvalho, E., Luís, C., \& de Freitas, V. (2004). Influence of the tannin structure on the disruption effect of carbohydrates on protein - tannin aggregates. Analytica Chimica Acta, 513(1), 135-140. https://doi.org/10.1016/j. aca.2003.08.072.

McRae, J. M., \& Kennedy, J. A. (2011). Wine and grape tannin interactions with salivary proteins and their impact on astringency: A review of current research. Molecules, 16 (3), 2348-2364. https://doi.org/10.3390/molecules16032348.

Mierczynska-Vasilev, A., \& Smith, P. A. (2015). Current state of knowledge and challenges in wine clarification. Australian Journal of Grape and Wine Research, 21, 615-626. https://doi.org/10.1111/ajgw.12198.

Nguela, J. M., Poncet-Legrand, C., Sieczkowski, N., \& Vernhet, A. (2016). Interactions of grape tannins and wine polyphenols with a yeast protein extract, mannoproteins and $\beta$-glucan. Food Chemistry, 210, 671-682. https://doi.org/10.1016/j. foodchem.2016.04.050.

Nilsson, L. (2013). Separation and characterization of food macromolecules using fieldflow fractionation: A review. Food Hydrocolloids, 30(1), 1-11. https://doi.org/ 10.1016/j.foodhyd.2012.04.007.

Pascal, C., Poncet-Legrand, C., Cabane, B., \& Vernhet, A. (2008). Aggregation of a proline-rich protein induced by epigallocatechin gallate and condensed tannins: Effect of protein glycosylation. Journal of Agricultural and Food Chemistry, 56(15), 6724-6732. https://doi.org/10.1021/jf800790d.

Poncet-Legrand, C., Cartalade, D., Putaux, J.-L., Cheynier, V., \& Vernhet, A. (2003). Flavan-3-ol aggregation in model ethanolic solutions: Incidence of polyphenol structure, concentration, ethanol content, and ionic strength. Langmuir, 19(25), 10563-10572. https://doi.org/10.1021/la034927z.

Quijada-Morín, N., Williams, P., Rivas-Gonzalo, J. C., Doco, T., \& Escribano-Bailón, M. T. (2014). Polyphenolic, polysaccharide and oligosaccharide composition of Tempranillo red wines and their relationship with the perceived astringency. Food Chemistry, 154, 44-51. https://doi.org/10.1016/j.foodchem.2013.12.101.

Ratanathanawongs-Williams, S. K., \& Giddings, J. K. (2000). Sample recovery. In M. E. Schimpf, M. D. Caldwell, \& J. Giddings (Eds.), Field-flow fractionation handbook (pp. 325-344). New York, NY, USA: Wiley-Interscience.

Reschiglian, P., Roda, B., Zattoni, A., Tanase, M., Marassi, V., \& Serani, S. (2014). Hollow-fiber flow field-flow fractionation with multi-angle laser scattering detection for aggregation studies of therapeutic proteins Field-Flow Fractionation. Analytical and Bioanalytical Chemistry, 406(6), 1619-1627. https://doi.org/10.1007/s00216013-7462-4.

Rigaux, G., Gheran, C. V., Callewaert, M., Cadiou, C., Voicu, S. N., Dinischiotu, A., ... Chuburu, F. (2017). Characterization of Gd loaded chitosan-TPP nanohydrogels by a multi-technique approach combining dynamic light scattering (DLS), asymmetrical flow-field-flow-fractionation (AF4) and atomic force microscopy (AFM) and design of positive contrast agents for molecular resonance imaging (MRI). Nanotechnology, 28(5), Article 055705. https://doi.org/10.1088/1361-6528/aa5188.

Righetti, P. G., \& D'Amato, A. (2017). Proteomics of grapevines and wines. In M. L. Colgrave (Ed.), Proteomics in food science: From farm to fork (pp. 405-414). Academic Press Inc. https://doi.org/10.1016/B978-0-12-804007-2.00024-2.

Riou, V., Vernhet, A., Doco, T., \& Moutounet, M. (2002). Aggregation of grape seed tannins in model wine-effect of wine polysaccharides. Food Hydrocolloids, 16(1), 17-23. https://doi.org/10.1016/s0268-005x(01)00034-0.

Roda, B., Zattoni, A., Reschiglian, P., Moon, M. H., Mirasoli, M., Michelini, E., et al. (2009). Field-flow fractionation in bioanalysis: A review of recent trends. Analytica Chimica Acta, 635(2), 132-143. https://doi.org/10.1016/j.aca.2009.01.015.

Santos-Buelga, C., \& de Freitas, V. (2009). Influence of phenolics on wine organoleptic properties. In Wine chemistry and biochemistry (pp. 529-570). New York: Springer.
Schimpf, M. E., Caldwell, K., \& Giddings, J. C. (2000). In M. E. Schimpf, K. Caldwell, \& J. C. Giddings (Eds.), Field flow fractionation handbook. John Wiley \& Sons. Retrieved from https://www.wiley.com/en-it/Field+Flow+Fractionation+Handbook-p-9780 471184300 .

Scollary, G. R., Pásti, G., Kállay, M., Blackman, J., \& Clark, A. C. (2012). Astringency response of red wines: Potential role of molecular assembly. Trends in Food Science \& Technology, 27(1), 25-36. https://doi.org/10.1016/j.tifs.2012.05.002.

Segarra, I., Lao, C., López-Tamames, E., \& De La Torre-Boronat, M. C. (1995). Spectrophotometric methods for the analysis of polysaccharide levels in winemaking products. American Journal of Enology and Viticulture, 46(4), 564-570. Retrieved from http://www.ajevonline.org/content/46/4/564.short.

Smith, P. A., McRae, J. M., \& Bindon, K. A. (2015). Impact of winemaking practices on the concentration and composition of tannins in red wine. Australian Journal of Grape and Wine Research, 21, 601-614. https://doi.org/10.1111/ajgw.12188.

Singleton, V. L., Orthofer, R., \& Lamuela-Raventós, R. M. (1999). Analysis of total phenols and other oxidation substrates and antioxidants by means of folin-ciocalteu reagent. In L. Packer (Ed.), 299. Methods in enzymology (pp. 152-178). Academic Press. https://www.sciencedirect.com/science/article/pii/S0076687999990171.

Smith, M. R., Penner, M. H., Bennett, S. E., \& Bakalinsky, A. T. (2011). Quantitative colorimetric assay for total protein applied to the red wine pinot noir. Journal of Agricultural and Food Chemistry, 59(13), 6871-6876. https://doi.org/10.1021/ jf200547u.

Soares, S., Mateus, N., \& de Freitas, V. (2007). Interaction of different polyphenols with bovine serum albumin (BSA) and human salivary $\alpha$-amylase (HSA) by fluorescence quenching. Journal of Agricultural and Food Chemistry, 55(16), 6726-6735. https:// doi.org/10.1021/jf070905x.

Sommer, S., Dickescheid, C., Harbertson, J. F., Fischer, U., \& Cohen, S. D. (2016) Rationale for haze formation after Carboxymethyl Cellulose (CMC) addition to red wine. Journal of Agricultural and Food Chemistry, 64(36), 6879-6887. https://doi. org/10.1021/acs.jafc.6b02479.

Springer, L. F., Sherwood, R. W., \& Sacks, G. L. (2016). Pathogenesis-Related proteins limit the retention of condensed tannin additions to red wines. Journal of Agricultural and Food Chemistry, 64(6), 1309-1317. https://doi.org/10.1021/acs.jafc.5b04906.

Thielking, H., Roessner, D., \& Kulicke, W.-M. (1995). Online coupling of flow field-flow fractionation and multiangle laser light scattering for the characterization of polystyrene particles. Analytical Chemistry, 67(18), 3229-3233. https://doi.org/ 10.1021/ac00114a020.

Van Sluyter, S. C., McRae, J. M., Falconer, R. J., Smith, P. A., Bacic, A., Waters, E. J., \& Marangon, M. (2015). Wine protein haze: Mechanisms of formation and advances in prevention. Journal of Agricultural and Food Chemistry, 63(16), 4020-4030. https:// doi.org/10.1021/acs.jafc.5b00047.

Vernhet, A. (2019). Red wine clarification and stabilization. In A. Morata (Ed.), Red wine technology (pp. 237-251). Academic Press. https://www.sciencedirect.com/sci ence/article/pii/B9780128143995000165.

Vincenzi, S., Marangon, M., Tolin, S., \& Curioni, A. (2011). Protein evolution during the early stages of white winemaking and its relations with wine stability. Australian Journal of Grape and Wine Research, 17(1), 20-27. https://doi.org/10.1111/j.17550238.2010.00113.x.

Waterhouse, A. L., Sacks, G. L., \& Jeffery, D. W. (2016a). Anthocyanins. In A. L. Waterhouse, G. L. Sacks, \& D. W. Jeffery (Eds.), Understanding wine chemistry (pp. 131-139). Chichester, UK: John Wiley \& Sons, Ltd. https://doi.org/10.1002/ 9781118730720.ch16.

Watrelot, A. A., Schulz, D. L., \& Kennedy, J. A. (2017). Wine polysaccharides influence tannin-protein interactions. Food Hydrocolloids, 63, 571-579. https://doi.org/ 10.1016/j.foodhyd.2016.10.010

Wigand, P., Tenzer, S., Schild, H., \& Decker, H. (2009). Analysis of protein composition of red wine in comparison with rosé and white wines by electrophoresis and highpressure liquid chromatography-mass spectrometry (HPLC-MS). Journal of Agricultural and Food Chemistry, 57(10), 4328-4333. https://doi.org/10.1021/ jf8034836.

Zattoni, A., Rambaldi, D. C., Reschiglian, P., Melucci, M., Krol, S., Garcia, A. M. C., .. Johann, C (2009). Asymmetrical flow field-flow fractionation with multi-angle light scattering detection for the analysis of structured nanoparticles. Journal of Chromatography A, 1216(52), 9106-9112. https://doi.org/10.1016/j. chroma.2009.06.037.

Zattoni, A., Roda, B., Borghi, F., Marassi, V., \& Reschiglian, P. (2014). Flow field-flow fractionation for the analysis of nanoparticles used in drug delivery. Journal of Pharmaceutical and Biomedical Analysis, 87, 53-61. https://doi.org/10.1016/j. jpba.2013.08.018. 